INTERAÇÃO DE HERBICIDAS E ADUBO FOLIAR SOBRE HÍBRIDOS DE MILHO

\title{
INTERATION OF HERBICIDS AND SEASONING LEAVES ON CORN HYBRIDS
}

\author{
CORTEZ ', M. G. ; CASTRO², F. C. ; SALOMONS² F.; OHSE$^{1}$, S. \\ 1- Docentes do Departamento de Fitotecnia e Fitossanidade, Curso de Agronomia - Universidade \\ Estadual de Ponta Grossa, Ponta Grossa/PR. \\ 2- Acadêmicos do curso de Agronomia da Universidade Estadual de Ponta Grossa, Departamento de \\ Fitotecnia e Fitossanidade, Ponta Grossa-PR
}

Email:mgcortez@uepg.bre sohse@uepg.br

\section{RESUMO:}

O objetivo do trabalho foi avaliar os efeitos da aplicação de diferentes herbicidas em pós-emergência e época de adubação via foliar sobre híbridos de milho. O experimento foi conduzido na Fazenda Escola da UEPG, Ponta Grossa/PR, delineado em blocos casualizados com 4 repetições. Os tratamentos constaram de três níveis do fator herbicida mesotrione (120 $\left.\mathrm{g} \mathrm{ha}^{-1}\right)$; atrazine $\left(1250 \mathrm{~g} \mathrm{ha}^{-1}\right)$ e mesotrione + atrazine; dois híbridos (30P70 e 30K75), duas épocas de aplicação de adubo foliar [0 e 7 dias após aplicação dos herbicidas (DAA)]. Avaliou-se a altura de plantas, número de folhas por planta, diâmetro de colmo, teor de clorofila e variáveis da produtividade. Detectou-se interação entre herbicidas e híbridos para número de folhas por planta aos 32 DAA, entre herbicidas e época de aplicação do adubo foliar para diâmetro de colmo aos 32 DAA, entre híbridos e épocas de aplicação do adubo foliar para grãos por fileira. $O$ híbrido 30P70 apresentou melhor desempenho quanto à altura de planta, de inserção da primeira espiga, número de espigas por planta e grãos por fileira e pior quanto à fitomassa de 1000 grãos, diâmetro e tamanho de espiga quando comparado ao $30 \mathrm{~K} 75$. O diâmetro de espiga foi maior quando da aplicação de mesotrione e o tamanho da espiga quando da aplicação da mistura mesotrione + atrazine. Não houve interações entre herbicidas, épocas de aplicação do adubo foliar e híbridos de milho em relação à aplicação dos herbicidas para as variáveis da produtividade.

Palavras-chave: Zea mays L., mesotrione, atrazine, adubação foliar.

\section{ABSTRACT:}

The objective of this paper is to assess the effects of the application of different weedkillers at powders-emergences and time of fertilizing through foliaceous on hybrids of corn. The experiment took place at the Farm School of the UEPG, Tip Grossa/PR, outlined in blocks randomized with 4 replications. The treatments consisted of three levels of the factor weedkiller (mesotrione (120 g ha-1); atrazine (1250 g ha-1) and mesotrione atrazine; two hybrids (30P70 and 30K75), application of foliaceous manure done twice [0 and 7 days after weedkillers application (DAA)]. The height of plants, number of leaves per plant, diameter of stem, tenor of chlorophyll, and variables of the productivity were assessed. Interaction was detected between weedkillers and hybrids for number of leaves per plant at 32 DAA between weedkillers and time of application of the foliaceous manure for diameter of stem at 32 DAA, between hybrids and times of application of the foliaceous manure for grains by row. The hybrid $30 \mathrm{P} 70$ presented 
better performance as to the height of plant, insertion of the first spike, number of spikes per plant and grains per row and the worst performance as to the phytomass of 1000 grains, diameter and size of spike when compared to 30K75. The diameter of ear was big throughout the application of mesotrione and the size of the spike when of the application of the mixture mesotrione atrazine. There were no interactions between weedkillers, times of application of the foliaceous manure and hybrids of corn regarding the application of the weedkillers for the variables of productivity.

Key words: Zea mays L., mesotrione, atrazine, leaf manuring.

\section{INTRODUÇÃO}

O milho (Zea mays L.) é um dos principais cereais cultivados em todo o mundo. Sua importância é devido à grande capacidade de adaptação a diferentes condições ambientais, ao seu valor nutricional para alimentação humana e animal e pela geração de renda, por meio da produção de grãos (OVEJERO et al., 2003). No Brasil, sua produção é voltada para o abastecimento interno, estando relacionada às cadeias produtivas de suínos e aves.

Apesar do Brasil ser o terceiro maior produtor mundial de milho, a produtividade média para a primeira safra $2014 / 15$ foi em torno de $4.995 \mathrm{~kg} \mathrm{ha}^{-1}$, sendo, porém 4,4\% superior a de 2013/14 (CONAB, 2016), considerada baixa quando comparada à de outros países como EUA (9.500 kg ha $\left.{ }^{-1}\right)$ e Argentina (7.800 kg ha-1). A produção nacional de milho na safra $2014 / 15$ foi de $30.262,9$ mil toneladas contra 31.652,6 toneladas na safra anterior (CONAB, 2016). No entanto, no Brasil, a produtividade na segunda safra vem superando a primeira, com média de $5.420 \mathrm{~kg} \mathrm{ha}^{-1}$ na safra 2015. Vários são os fatores que podem influenciar esta baixa produtividade e, dentre eles, destaca-se a interferência das plantas daninhas às culturas agrícolas.

O processo de interferência das plantas daninhas na cultura do milho causa problemas no desenvolvimento da planta, no processo produtivo, na qualidade dos grãos e, na operacionalização da colheita (KARAM; MELHORANÇA, 2004). Além disso, dificulta o manejo de práticas culturais, contribuindo para o aparecimento de doenças e pragas (SILVA et al., 1998).

O controle químico de plantas daninhas é o mais utilizado atualmente na cultura do milho, apresentando vantagens, devido à ação rápida e eficaz no controle de ampla gama de espécies. Dentre os herbicidas utilizados, destacam-se os aplicados em pós-emergência (OVEJERO et al., 2003), principalmente em sistema de cultivo de semeadura direta.

Dentre os herbicidas registrados para a cultura do milho encontra-se 0 mesotrione, pertencente ao grupo químico das tricetonas, e a atrazine, do grupo químico das triazinonas, ambos seletivos à cultura do milho (OVEJERO et al., 2003). 
A seletividade dos herbicidas às plantas cultivadas possibilita o controle na linha sem causar danos ao sistema radicular e alta operacionalidade em grandes áreas. Pode ser definida como a medida da resposta diferencial das espécies de plantas à aplicação de uma determinada molécula (JÚNIOR, 2001; FILHO, 2003). O grau de seletividade de um herbicida às culturas também pode estar relacionado à tolerância diferencial (COLE, 1994) entre híbridos.

A aplicação de herbicidas em pós-emergência expõe a cultura do milho, a inúmeras situações de manejo, em coincidência com a utilização de outros agroquímicos. Com isso, a adição de adjuvantes, nutrientes ou inseticidas à calda contendo herbicida pode modificar a capacidade da planta em tolerá-lo, resultando em perda da seletividade ou da eficácia no controle das plantas daninhas (GASSEN, 2002). Por isso, tornam-se necessários estudos das possíveis interações entre agroquímicos utilizados simultaneamente, melhor, para orientar técnicos e produtores.

O trabalho teve como objetivo avaliar os efeitos de herbicidas aplicados em pós-emergência, associados a diferentes épocas de aplicação de adubo via foliar, sobre dois híbridos de milho, em sistema de semeadura direta.

\section{MATERIALE MÉTODOS}

O experimento foi conduzido na área experimental da Fazenda Escola pertencente à Universidade Estadual de Ponta Grossa (UERPG), Ponta Grossa/PR. O clima da região, segundo KÖEPPEN, é do tipo Cfb (subtropical, sem estação seca e temperatura média do mês mais quente menor $22^{\circ} \mathrm{C}$ ), sempre úmido, quente temperado, sem estação seca definida e com geadas frequentes no inverno. O solo é classificado como Cambissolo Háplico distrófico de textura média (EMBRAPA, 1999). A análise química do solo nos primeiros $20 \mathrm{~cm}$ apresentou: $\mathrm{pH} \mathrm{CaCl}_{2}: 4,6$; $\mathrm{P}: 5,4 \mathrm{mg} \mathrm{dm}^{-3}$; $\mathrm{K}^{+}: 0,32 \mathrm{cmol}_{\mathrm{c}} \mathrm{dm}^{-3} ; \mathrm{Ca}^{+2}: 3,5 \mathrm{cmol}_{\mathrm{c}} \mathrm{dm}^{-3} ; \mathrm{Mg}^{+2}: 2,0 \mathrm{cmol}_{\mathrm{c}} \mathrm{dm}^{-3} ; \mathrm{H}^{+}+\mathrm{Al}^{+3}: 8,36 \mathrm{cmol}_{\mathrm{c}} \mathrm{dm}^{-3}$; CTC (capacidade de troca de cátions): $6,12 \mathrm{cmol}_{\mathrm{c}} \mathrm{dm}^{-3} \mathrm{eV}$ (Saturação de bases): 41\%.

O delineamento experimental adotado foi o de blocos casualizados, em esquema fatorial $3 \times 2 \times 2$, sendo 3 herbicidas (mesotrione, atrazine e mistura); 2 épocas de aplicação do adubo foliar (junto com os herbicidas e 7 DAA - dias após a aplicação) e 2 híbridos de milho (Pioneer 30P70 e 30K75), constituindo-se então de 12 tratamentos, repetidos 4 vezes (Tabela 1). A aplicação do adubo foliar (Wuxal 16-16-12) foi realizada no dia da aplicação dos herbicidas (0 dias após a aplicação - DAA) e 7 DAA. 
Tabela 1. Tratamentos avaliados nos híbridos. UEPG, Ponta Grossa - PR.

\begin{tabular}{l|cc}
\hline \multicolumn{1}{c}{ TRATAMENTOS } & \multicolumn{2}{c}{ DOSE } \\
\cline { 2 - 3 } & g i.a ha-1 & L p.c ha-1 \\
\hline 1- H1 + Mesotrione + adubo foliar & 120 & $0,250+1,5$ \\
$2-\mathrm{H} 1+$ Mesotrione + adubo foliar 7 DAA & 120 & $0,250+1,5$ \\
$3-\mathrm{H} 1+$ Atrazine + adubo foliar & 1250 & $2,5+1,5$ \\
$4-\mathrm{H} 1+$ Atrazine + adubo foliar 7 DAA & 1250 & $2,5+1,5$ \\
$5-\mathrm{H} 1+$ Mesotrione + Atrazine + adubo foliar & $120+1250$ & $0,250+2,5+1,5$ \\
$6-\mathrm{H} 1+$ Mesotrione + Atrazine + adubo foliar 7 DAA & $120+1250$ & $0,250+2,5+1,5$ \\
$7-\mathrm{H} 2+$ Mesotrione + adubo foliar & 120 & $0,250+1,5$ \\
$8-\mathrm{H} 2+$ Mesotrione + adubo foliar 7 DAA & 120 & $0,250+1,5$ \\
$9-\mathrm{H} 2+$ Atrazine + adubo foliar & 1250 & $2,5+1,5$ \\
$10-\mathrm{H} 2+$ Atrazine + adubo foliar 7 DAA & 1250 & $2,5+1,5$ \\
$11-\mathrm{H} 2+$ Mesotrione + Atrazine + adubo foliar & $120+1250$ & $0,250+2,5+1,5$ \\
$12-\mathrm{H} 2+$ Mesotrione + Atrazine + adubo foliar 7 DAA & $120+1250$ & $0,250+2,5+1,5$ \\
\hline
\end{tabular}

g i.a. ha $^{-1}=$ gramas de ingrediente ativo por hectare; $L$ p.c ha ${ }^{-1}=$ litros de produto comercial por hectare; $\mathrm{H} 1=$ híbrido 1 (30K75); H2= híbrido 2 (30P70)

O experimento foi instalado em área conduzida sob sistema de plantio direto, tendo permanecido em pousio durante o inverno de 2006, após o qual foi efetuada a dessecação das plantas daninhas presentes na área, onde predominavam papuã (Brachiaria plantaginea), ançarinha-branca (Chenopodium album L.), leiteira (Euphorbia heterophylla L.), guaxuma (Sida cordifolia L.), corda-de-viola (Ipomoea sp.), milhã (Digitaria horizontalis) e manchas com trapoeraba (Commelina virginica). A dessecação foi realizada com glyphosate $\left(1,5 \mathrm{~L} \mathrm{ha}^{-1}\right)$. Após 35 dias da primeira aplicação, realizou-se aplicação complementar de glyphosate na mesma dose, sendo a semeadura realizada 12 dias após esta última dessecação.

A semeadura foi realizada mecanicamente no dia 13 de novembro de 2006, distribuindo-se 5,6 sementes por $m$ linear, utilizando-se espaçamento de 0,80 m, com o objetivo de obter aproximadamente 70.000 sementes $^{-1}{ }^{-1}$, e uma população de 63.000 a 65.000 plantas ha ${ }^{-1}$. Cada unidade experimental foi composta por 4 linhas de $6 \mathrm{~m}$ de comprimento, perfazendo área total de $19,2 \mathrm{~m}^{2}$ e área útil de $6,4 \mathrm{~m}^{2}$. O híbrido 30P70 é tipo simples, precoce, grão amarelo-alaranjado, semiduro. O híbrido $30 \mathrm{~K} 75$ é tipo 
simples, semiprecoce, grão alaranjado, semiduro.

A adubação de semeadura constou de $300 \mathrm{~kg} \mathrm{ha}^{-1}$ de adubo na fórmula 10-2020. A adubação em cobertura foi realizada com a cultura do milho entre 4 e 6 folhas expandidas, 37 dias após a semeadura (DAS), com $200 \mathrm{~kg} \mathrm{ha}^{-1}$ de uréia, fornecendo 90 $\mathrm{kg} \mathrm{ha}^{-1}$ de N.

A aplicação dos herbicidas foi realizada quando a cultura de milho apresentava 4 a 6 folhas expandidas, 36 DAS, utilizando-se pulverizador costal pressurizado por $\mathrm{CO}_{2}$, com pressão constante de 3,0 bar. A barra de aplicação continha 6 bicos do tipo leque, modelo Turbo Teejet 110.02 , espaçados de $0,50 \mathrm{~m}$, com ângulo de $110^{\circ}$. $\mathrm{O}$ volume de calda aplicado foi de $200 \mathrm{~L} \mathrm{ha}^{-1}$, tanto para herbicidas como para o adubo foliar. Todas as unidades experimentais, após a aplicação dos tratamentos, foram mantidas livres da competição de plantas daninhas por meio de capinas manuais, objetivando evitar a interferência de outras espécies não controladas, sobre a cultura.

Foram realizadas 2 aplicações de inseticidas, a primeira aos 32 DAS, utilizando-se piretróide ( $\left.0,1 \mathrm{~L} \mathrm{ha}^{-1}\right)$ e a segunda, aos 45 DAS utilizando-se lufenuron (0,3 $\left.\mathrm{L} \mathrm{ha}^{-1}\right)$. As aplicações dos inseticidas foram realizadas quando a cultura encontrava-se na fase de "cartucho" 5 a 8 folhas expandidas, fase em que é mais susceptível ao ataque da lagarta-do-cartucho (Spodoptera frugiperda).

Durante o ciclo da cultura do milho avaliou-se: altura de plantas, número de folhas expandidas, diâmetro de colmo aos 0, 16, 32 e 40 DAA; teor de clorofila nas folhas aos 0, 24 DAA; porcentagem de fitotoxicidade aos 8, 16, 24 DAA segundo a Escala de Fitotoxicidade (SBCPD, 1995); quantidade de plantas daninhas aos 152 dias do ciclo, quando foi efetuada a colheita. As medições de altura de plantas, número de folhas expandidas, diâmetro de colmo, foram realizadas em 4 plantas por unidade experimental (UE). O teor de clorofila foi determinado em 5 plantas por UE, sempre no terço médio da última folha expandida com auxílio do clorofilômetro Minolta SPAD-502.

Durante a fase reprodutiva da cultura determinou-se o número de espigas por planta e altura de inserção da primeira espiga (56 DAA), avaliando-se 5 plantas por UE. Após a colheita, efetuaram-se as seguintes avaliações relacionadas à produtividade: comprimento de espiga, diâmetro de espiga, número de fileiras por espiga, número de grãos por fileira, fitomassa de 1000 grãos, teor de água nos grãos e a produção por hectare.

Os dados foram submetidos à análise da variância, pelo teste de $\mathrm{F}$, seguida pela aplicação do teste Tukey para comparação das médias a $5 \%$ de probabilidade.

\section{RESULTADOS E DISCUSSÃO}

Durante todo o período avaliado, o híbrido $30 \mathrm{P} 70$ apresentou aproximadamente $15 \%$ a mais de altura que o híbrido $30 \mathrm{~K} 75$ (Tabela 2). Até os 32 DAA 
verificaram-se diferenças significativas na altura de plantas de milho, para os herbicidas testados. O herbicida mesotrione aplicado sozinho levou as plantas de milho a apresentarem maior altura do que quando aplicado em mistura com atrazine (Tabela 2).

A diferença entre o número de folhas por plantas de milho foi significativa antes da aplicação dos herbicidas e do adubo, sendo maior para o híbrido 30P70 (Tabela 2). Porém, aos 32 DAA dos herbicidas, o híbrido 30P70 não apresentou diferenças entre os herbicidas testados para está variável. O híbrido 30K75 apresentou redução no número de folhas por planta, quando do tratamento com mesotrione + atrazine aos 32 DAA (Tabela 3). Não foram observadas influências da época de aplicação do adubo sobre esta variável. As características genéticas e morfológicas podem explicar o comportamento diferenciado desta variável, entre os híbridos testados.

TABELA 2. Altura de plantas e número de folhas por planta em híbridos de milho, influenciadas por herbicidas e época de aplicação de adubo foliar. UEPG, Ponta Grossa-PR.

\begin{tabular}{|c|c|c|c|c|c|c|c|c|}
\hline \multirow{2}{*}{ TRATAMENTOS } & \multicolumn{4}{|c|}{ Altura de plantas $(\mathrm{cm})$} & \multicolumn{4}{|c|}{ Número de folhas por planta } \\
\hline & 0 DAA & $16 \mathrm{DAA}$ & $32 \mathrm{DAA}$ & $40 \mathrm{DAA}$ & $0 \mathrm{DAA}$ & $16 \mathrm{DAA}$ & $32 \mathrm{DAA}$ & $40 \mathrm{DAA}$ \\
\hline \multicolumn{9}{|l|}{ HERBICIDAS } \\
\hline Mesotrione & $86,5 a b$ & $164,0 \mathrm{a}$ & $242,1 \mathrm{a}$ & $237,2 \mathrm{a}$ & $5,6 \mathrm{a}$ & $6,9 \mathrm{a}$ & $10,8 \mathrm{a}$ & $14,3 \mathrm{a}$ \\
\hline Atrazine & $89,2 \mathrm{a}$ & $168,7 \mathrm{a}$ & $230,5 a b$ & $245,0 \mathrm{a}$ & $5,8 \mathrm{a}$ & $7,2 \mathrm{a}$ & $11,1 \mathrm{a}$ & $14,8 \mathrm{a}$ \\
\hline $\begin{array}{l}\text { Mesotrione + } \\
\text { atrazine }\end{array}$ & $82,8 \quad b$ & $160,1 \mathrm{a}$ & 214,7 b & 244,9 a & $5,7 \mathrm{a}$ & $7,1 \mathrm{a}$ & 10,6 a & $14,5 \mathrm{a}$ \\
\hline \multicolumn{9}{|l|}{ ÉPOCAS } \\
\hline $0 D D A A^{*}$ & $85,3 a$ & $162,1 \mathrm{a}$ & $228,3 \mathrm{a}$ & $242,7 \mathrm{a}$ & $5,7 \mathrm{a}$ & $7,1 \mathrm{a}$ & $10,7 \mathrm{a}$ & $14,6 \mathrm{a}$ \\
\hline $7 \mathrm{DAA}$ & $87,0 \mathrm{a}$ & 166,4 a & 229,9 a & 241,9 a & $5,7 \mathrm{a}$ & $7,1 \mathrm{a}$ & $11,1 \mathrm{a}$ & $14,5 \mathrm{a}$ \\
\hline \multicolumn{9}{|l|}{ HÍBRIDOS } \\
\hline $30 K 75$ & $76,1 \mathrm{~b}$ & $154,6 \mathrm{~b}$ & $209,5 \mathrm{~b}$ & $228,5 \mathrm{~b}$ & $5,1 \mathrm{~b}$ & $7,0 \mathrm{a}$ & $10,9 \mathrm{a}$ & $14,4 \mathrm{a}$ \\
\hline $30 \mathrm{P} 70$ & $96,2 \mathrm{a}$ & $174,1 \mathrm{a}$ & 248,7 a & 256,2 a & $6,3 \mathrm{a}$ & $7,2 \mathrm{a}$ & 10,9 a & $14,7 \mathrm{a}$ \\
\hline CV (\%) & 8,1 & 7,2 & 12,8 & 4,1 & 8,5 & 5,3 & 6,5 & 5,8 \\
\hline
\end{tabular}

1-DAA= dias após a aplicação dos herbicidas.

2- Médias seguidas da mesma letra, comparadas na coluna, não diferem estatisticamente pelo teste de Tukey $(P>0.05)$.

ODAA= aplicação do adubo junta com o herbicida. 
Antes da aplicação dos herbicidas (0 DAA), foi significativa a diferença no diâmetro de colmo, realçando a diferença de desenvolvimento inicial, entre os híbridos de milho testados. Nesta ocasião, o híbrido 30P70 apresentou colmo com diâmetro 18,7\% maior que o híbrido 30K75 (Tabela 4), todavia, no decorrer do período avaliado, não ocorreram diferenças significativas, entre os híbridos, para esta variável (Tabela 4).

O teor de clorofila apresentou-se em quantidade equivalente, nas folhas de plantas de milho, de todos os tratamentos, tanto no dia da aplicação dos herbicidas e adubos, quanto aos 24 DAA, demonstrando que os tratamentos testados não influenciaram esta variável (Tabela 4).

TABELA 3. Número de folhas por planta de milho influenciado pela interação herbicida x híbrido. Ponta Grossa-PR.

\begin{tabular}{llll}
\hline \multicolumn{4}{c}{ Número de folhas por planta aos 32 DAA } \\
\hline HERBICIDA-HIBRÍDO & $\mathbf{3 0 K 7 5}$ & $\mathbf{3 0 P 7 0}$ & Média herbicida \\
\hline Mesotrione & 11,42 a A & 10,51 a B & 10,97 a \\
Atrazine & 11,01 a A & 11,14 a A & 11,08 a \\
Mesotrione + Atrazine & 10,11 b B & 11,00 a A & 10,56 a \\
\hline Média híbridos & 10,85 A & 10,88 A & \\
CV (\%) & 6,45 & & \\
\hline
\end{tabular}

1-DAA = dias após a aplicação dos herbicidas.

2- Médias seguidas da mesma letra minúscula, comparadas na coluna e maiúscula na linha, não diferem estatisticamente pelo teste de Tukey $(P>0.05)$.

O teor de clorofila na folha é utilizado para predizer o nível de nitrogênio nas plantas, uma vez que a quantidade deste pigmento correlaciona-se com o teor de $\mathrm{N}$ na planta (BOOIJ et al., 2000). Isto ocorre devido 50 a $70 \%$ do $\mathrm{N}$ total das folhas serem integrante de moléculas de clorofilas associadas aos cloroplastos (ARGENTA et al., 2001). Como a atrazine é um herbicida que inibe o transporte de elétrons no fotossistema II, na fase fotoquímica da fotossíntese, nota-se que o mesmo foi seletivo, mesmo quando a aplicação ocorreu associada ao adubo foliar, para ambos os híbridos, uma vez que não causou clorose no milho, consequentemente, não afetando a síntese de clorofila (Tabela 4).

Aos 32 DAA, o diâmetro de colmo foi influenciado pelos herbicidas e época de aplicação do adubo foliar. Houve redução média de $7 \%$, no diâmetro de colmo de plantas de milho tratadas com (mesotrione + atrazine). Quando o adubo foliar foi aplicado 7 DAA dos herbicidas, o diâmetro de colmo foi em média 4\% maior para as plantas tratadas com mesotrione. Entre os herbicidas testados, o mesotrione apresentou maior diâmetro de colmo, quando o adubo foliar foi aplicado aos 7 DAA. $O$ diâmetro de colmos de plantas de milho foi menor, quando da aplicação conjunta do 
adubo foliar com os herbicidas, independentemente do produto utilizado (Tabela 5).

TABELA 4. Diâmetro de colmo e teor de clorofila em folhas de plantas de híbridos de milho influenciadas por herbicidas e épocas de aplicação de adubo foliar. UEPG, Ponta Grossa-PR.

\begin{tabular}{ccccccc}
\hline & \multicolumn{5}{c}{ Diâmetro de colmo $(\mathbf{c m})$} & \multicolumn{2}{c}{ Clorofila $\left(\mathbf{m g ~ d m}^{-2}\right)$} \\
\cline { 2 - 7 } TRATAMENTOS & 0 DAA & 16 DAA & 32 DAA & 40 DAA & 0 DAA & 24 DAA \\
\hline HERBICIDAS & & & & & & \\
Mesotrione & $1,52 \mathrm{a}$ & $2,18 \mathrm{a}$ & $2,08 \mathrm{a}$ & $2,04 \mathrm{a}$ & $41,52 \mathrm{a}$ & $48,41 \mathrm{a}$ \\
Atrazine & $1,55 \mathrm{a}$ & $2,21 \mathrm{a}$ & $2,03 \mathrm{a}$ & $2,09 \mathrm{a}$ & $41,73 \mathrm{a}$ & $48,84 \mathrm{a}$ \\
Mesotrione + atrazine & $1,45 \mathrm{a}$ & $2,14 \mathrm{a}$ & $1,96 \mathrm{~b}$ & $2,06 \mathrm{a}$ & $43,00 \mathrm{a}$ & $48,44 \mathrm{a}$ \\
ÉPOCAS & & & & & & \\
0 DAA & $1,50 \mathrm{a}$ & $2,16 \mathrm{a}$ & $1,98 \mathrm{~b}$ & $2,09 \mathrm{a}$ & $42,38 \mathrm{a}$ & $48,22 \mathrm{a}$ \\
7 DAA & $1,51 \mathrm{a}$ & $2,20 \mathrm{a}$ & $2,06 \mathrm{a}$ & $2,04 \mathrm{a}$ & $41,80 \mathrm{a}$ & $48,91 \mathrm{a}$ \\
HÍBRIDOS & & & & & & \\
30K75 & $1,35 \mathrm{~b}$ & $2,18 \mathrm{a}$ & $2,03 \mathrm{a}$ & $2,06 \mathrm{a}$ & $42,75 \mathrm{a}$ & $48,35 \mathrm{a}$ \\
30P70 & $1,66 \mathrm{a}$ & $2,18 \mathrm{a}$ & $2,02 \mathrm{a}$ & $2,07 \mathrm{a}$ & $41,42 \mathrm{a}$ & $48,78 \mathrm{a}$ \\
CV (\%) & 13,88 & 5,55 & 2,90 & 6,21 & 6,90 & 3,94 \\
\hline
\end{tabular}

1-DAA = dias após a aplicação dos herbicidas.

2- Médias seguidas da mesma letra, comparadas na coluna, não diferem estatisticamente pelo teste de Tukey $(\mathrm{P}>0.05)$.

ODAA= aplicação do adubo junta com o herbicida.

Para altura de inserção da primeira espiga, número de fileiras por espiga e fitomassa de mil grãos houve diferenças entre os híbridos testados, sendo que o híbrido 30P70 apresentou em média, $12 \%$ a mais em altura de inserção, no número de fileiras por espiga e no número de grão por fileira que o híbrido 30K75. Já o híbrido 30K75 apresentou aumento significativo de $9 \%$, na fitomassa de mil grãos (Tabela 6). Os fatores herbicidas e épocas de aplicação do adubo foliar não afetaram a fitomassa de mil grãos.

O número de espigas por planta apresentou diferenças significativas entre os híbridos e entre as épocas de aplicação do adubo foliar. As plantas do híbrido 30P70, que receberam adubo foliar aos 7 DAA dos herbicidas, apresentaram $9 \%$ mais espigas por planta do que o híbrido 30K75 (Tabela 6).

O diâmetro e o comprimento da espiga, de forma semelhante, foram influenciados significativamente, pelos herbicidas e pelos híbridos testados. As plantas do híbrido 30K75 apresentaram maior diâmetro, e as tratadas com (mesotrione + atrazine), apresentaram maior comprimento da espiga (Tabela 6). 
TABELA 5. Diâmetro de colmo de plantas de milho influenciado pela interação herbicida x época de aplicação de adubo foliar. UEPG, Ponta Grossa-PR.

\begin{tabular}{|c|c|c|c|}
\hline \multirow{2}{*}{ Herbicida/Época } & \multicolumn{3}{|c|}{ Diâmetro de Colmo aos 32 DAA (cm) } \\
\hline & O DAA ${ }^{*}$ & 7 DAA & Média Herbicida \\
\hline Mesotrione & $2,02 \mathrm{a} \quad \mathrm{B}$ & 2,13 a $A$ & $2,08 \mathrm{a}$ \\
\hline Atrazine & 2,05 a $A$ & $2,01 \mathrm{bA}$ & $2,03 a$ \\
\hline $\begin{array}{l}\text { Mesotrione + } \\
\text { atrazine }\end{array}$ & $1,88 \quad b \quad B$ & $2,05 \mathrm{bA}$ & $1,96 b$ \\
\hline Média Épocas & $1,98 \mathrm{~B}$ & $2,06 \mathrm{~A}$ & \\
\hline CV (\%) & 2,90 & & \\
\hline
\end{tabular}

1- DAA= dias após a aplicação dos herbicidas. ${ }^{2}$ Médias seguidas da mesma letra minúscula, comparadas na coluna e maiúscula na linha, não diferem estatisticamente pelo teste de Tukey $(P>0.05)$.

"O DAA= aplicação do adubo junta com o herbicida.

A produtividade máxima alcançada foi de $9862,8 \mathrm{~kg} \mathrm{ha}^{-1}$, com as plantas tratadas com (mesotrione + atrazine). Embora, as diferenças de produtividade entre os tratamentos testados não tenham sido significativas, verificou-se em média, perto de $500 \mathrm{~kg} \mathrm{ha}^{-1}$ de milho produzido a menos, nos demais tratamento. Sendo que a diferença entre o melhor e o pior (mesotrione) tratamento, foi de $700 \mathrm{~kg} \mathrm{ha}^{-1}$ de milho (Tabela 6).

No milho, a produtividade é determinada basicamente pelo número de grãos por unidade de área e, em menor escala, pela fitomassa individual dos grãos (RICHARDS, 2000). O híbrido 30P70 apresentou em relação ao híbrido 30K75 menor fitomassa de 1000 grãos menos fileiras de grãos por espiga, porém apresentou maior número de grãos por fileira e maior número de espigas, o que resultou em maior número de grãos por planta, 889,9 para o híbrido 30P70 e, 845,4 para o híbrido $30 \mathrm{~K} 75$ (Tabela 6). Esse fato explica porque a produtividade apresentou-se estatisticamente igual entre os híbridos. Contudo, ANDRADE (1996) evidenciou que a diminuição de 70 a $80 \%$ do número de grãos proporcionou $30 \%$ de aumento de fitomassa nos grãos remanescentes, demonstrando que o milho não apresenta a capacidade de compensar a perda de grãos pelo incremento em fitomassa.a perda de grãos pelo incremento em fitomassa. 
TABELA 6. Altura de inserção da primeira espiga (AIPE); número de espigas por planta (NEP); diâmetro da espiga (DE); comprimento da espiga (CE); fileiras por espiga (FE); grãos por fileira (GF); produtividade $(P)$ e fitomassa de mil grãos (FMG) de milho influenciadas por herbicidas, época de aplicação de adubo foliar e híbridos. UEPG, Ponta Grossa-PR.

\begin{tabular}{ccccccccc}
\hline \multirow{2}{*}{ TRATAMENTOS } & AIPE & NEP & DE & CE & FE & GF & FMG & $P$ \\
\cline { 2 - 8 } & $(\mathrm{cm})$ & (no) & (cm) & (cm) & (no) & (no) & (g) & $\left(\mathrm{kg} \mathrm{ha}^{-1}\right)$ \\
\hline
\end{tabular}

\section{HERBICIDAS}

Mesotrione

Atrazine

108 a 1,6 a

4,7 a

$18,1 \mathrm{ab} \quad 13,7 \mathrm{a}$

39,1 a

307,1 a

9162,6 a

Atrazine

112 a 1,8 a

4,6 b

17,7 b 13,4 a 39,0 a 309,7 a 9288,5 a

Mesotrione +

111 a 1,6 a

$4,7 \mathrm{ab}$

18,3 a 13,3 a

39,2 a $\quad 305,2$ a $\quad 9862,8$ a

atrazine

ÉPOCAS

0 DAA*

7 DAA

109 a $\quad 1,7$ a $\quad 4,6$

18,0 a 13,5 a

39,4 a $\quad 308,2$ a $\quad 9284,9$ a

112 a 1,5

4,7 a

18,1 a 13,5 a

38,9 a $\quad 306,5$ a $\quad 9590,4 a$

\section{HÍBRIDOS}

$30 K 75$

103 b 1,6 b 4,8 a $\quad 18,6$ a 14,4 a $\quad 37,5$ b 321,5 a 9497,5 a

$30 \mathrm{P} 70$

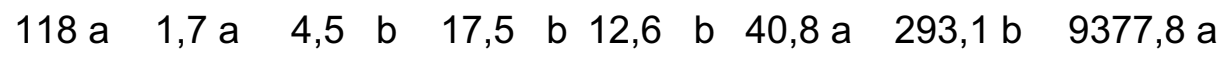

CV (\%)

$5,70 \quad 14,9 \quad 2,5$

3,2

5,6

4,8

5,7

11,5

1-DAA = dias após a aplicação dos herbicidas; ${ }^{2}$ Médias seguidas da mesma letra, comparadas na coluna, não diferem estatisticamente entre si pelo teste de Tukey ( $P>0.05)$; 0 DAA= aplicação do adubo junto com o herbicida.

O número de grãos por fileira foi maior para híbrido 30P70, independente da época em que se aplicou o adubo. Porém, o híbrido 30K75, expressou maior número de grãos por fileira, quando o adubo foliar foi aplicado 7 DAA dos herbicidas (Tabela 7).

As injúrias observadas pelos tratamentos, até os 24 DAA, foram: manchas amareladas e coloração verde pálido nas folhas, e ainda redução no desenvolvimento das plantas. Após este período, as plantas apresentaram recuperação, evidenciando desenvolvimento normal (Tabela 8). Entre os híbridos testados, o 30K75 aparentou ser o mais sensível aos produtos utilizados. O tratamento que resultou em maior fitotoxicidade, para ambos híbridos, foi a aplicação de mesotrione + atrazine junto com o adubo foliar. Não foi possível relacionar a época de aplicação do adubo foliar com os sintomas fitotóxicos observados (Tabela 8). 
TABELA 7. Número de grãos por fileira de espigas de milho influenciado pela época de aplicação do adubo foliar x híbrido. Ponta Grossa-PR.

\begin{tabular}{llll}
\hline Época / Híbrido & 30P70 & 30K75 & Média \\
\hline O DAA $^{*}$ & 40,15 a A & 38,54 a B & 39,34 a \\
7 DAA & 41,37 a A & 36,46 b B & $38,91 \mathrm{a}$ \\
MÉDIAS & 40,76 A & 37,50 B & \\
CV (\%) & 4,84 & & \\
\hline
\end{tabular}

1- Médias seguidas da mesma letra minúscula, comparadas na coluna e maiúscula na linha, não diferem estatisticamente pelo teste de Tukey $(P>0.05)$.

"O DAA= aplicação do adubo junta com o herbicida.

TABELA 8. Valores de fitointoxicação das plantas de milho após a aplicação dos tratamentos. UEPG, Ponta Grossa-PR, 2006/2007

\begin{tabular}{|c|c|c|c|c|c|}
\hline \multirow[b]{2}{*}{ Híbrido } & \multirow{2}{*}{$\begin{array}{r}\text { TRATAMENTOS } \\
\text { Tratamentos }\end{array}$} & \multicolumn{3}{|c|}{ \% Fitointoxicação } & \multirow[b]{2}{*}{ Média } \\
\hline & & $8 \mathrm{DAA}^{1}$ & 16 DAA & 24 DAA & \\
\hline \multirow{6}{*}{$30 K 75$} & mesotrione+adubo foliar & 11,2 & 12,5 & 8,2 & 10,7 \\
\hline & mesotrione+adubo foliar 7DAA & 17,5 & 12,5 & 7,0 & 12,3 \\
\hline & atrazine+adubo foliar & 13,2 & 12,5 & 4,0 & 9,9 \\
\hline & atrazine+adubo foliar 7DAA & 16,2 & 11,2 & 5,8 & 11,1 \\
\hline & (atraz+mesot)+adubo foliar & 23,8 & 20,0 & 15,0 & 19,6 \\
\hline & (atraz+mesot)+adubo foliar 7DAA & 16,2 & 17,5 & 10,8 & 14,8 \\
\hline \multirow{6}{*}{ 30P70 } & mesotrione+adubo foliar & 16,2 & 15,0 & 8,8 & 13,3 \\
\hline & mesotrione+adubo foliar 7DAA & 15,0 & 15,0 & 10,8 & 13,6 \\
\hline & atrazine+adubo foliar & 10,8 & 8,8 & 3,5 & 7,7 \\
\hline & atrazine+adubo foliar 7DAA & 8,8 & 12,5 & 3,5 & 8,2 \\
\hline & (atraz+mesot)+adubo foliar & 14,5 & 13,8 & 13,2 & 13,8 \\
\hline & (atraz+mesot)+adubo foliar 7DAA & 8,8 & 7,5 & 3,5 & 6,6 \\
\hline
\end{tabular}

1-DAA = dias após a aplicação dos herbicidas.

3- Escala de Fitotoxicidade (SBCPD, 1995), onde 0\% equivale a plantas sem injúrias ou nenhum sintoma visível, e $100 \%$ equivale a injúrias muito severas, sem recuperação da cultura. 
Observou-se de modo geral, que os efeitos de fitotoxicidade diminuíram no decorrer das avaliações, mostrando a capacidade dos híbridos em detoxicar os efeitos ocasionados pelos herbicidas e épocas de aplicação do adubo foliar a que foram submetidos (Tabela 8). Porém, para López OVEJERO (2000) e DAMIÃO-FILHO et al. (1996) comentam que, mesmo quando os sintomas de fitotoxicidade no milho não são aparentes, ainda podem ocorrer reduções na produtividade final da cultura. $O$ ano agrícola de 2006/2007 apresentou um regime de chuvas bem distribuído ao longo de todo o tempo em que a cultura permaneceu em campo, não havendo períodos significativos de estiagem que pudessem comprometer o crescimento e desenvolvimento das plantas.

\section{CONCLUSÕES}

Considerando as condições em que o experimento foi realizado, concluiu-se que a produtividade dos híbridos utilizados no experimento não foi afetada pelos herbicidas mesotrione e atrazine aplicados sozinhos ou em mistura e as épocas de aplicação do adubo foliar conjunta com os herbicidas ou após a aplicação destes, não alterou o comportamento dos híbridos.

\section{REFERÊNCIAS}

ARGENTA, G.; SILVA, P.R.F.; BORTOLINI, C.G.; FORSTHOFER, E.L.; STRIEDER, M.L. Relação da leitura do clorofilômetro com os teores de clorofila extraível e de nitrogênio na folha de milho. Revista Brasileira de Fisiologia Vegetal, v.13, n.2, p.158$167,2001$.

COELHO, A.M.; CRUZ, J.C.; PEREIRA FILHO, I.A. Rendimento do milho no Brasil: chegamos ao máximo? Piracicaba: POTAFOS, (Informações Agronômicas, 101), p.1$12,2003$.

CONAB. Companhia Nacional de Abastecimento. Comparativo da área, produtividade e produção safra 2005/2006 e 2006/2007. Disponível em 08/abr/2007: $<$ http://www.conab.gov.br/>. Acesso em: 23/jul/2007.

CONAB. Companhia Nacional de Abastecimento. Acompanhamento da Safra Brasileira de Grãos 2009/2010 - Décimo Segundo Levantamento - Set/2010. Milho $1^{\text {a }}$ safra. Disponível em set/2010: http://www.conab.gov.br/OlalaCMS/uploads/arquivos/ e05515f8222082610088f5a2376c6af..pdf. Acesso em: 07/fev/2011. 
DAMIÃO FILHO, C.F.; MÔRO, F.V.; TAVEIRA, L.R. Respostas de híbridos de milho ao nicosulfuron. I - Aspectos biológicos e da produção. Planta Daninha, Viçosa, v.14, p.3-13, 1996.

EMBRAPA. Centro Nacional de Pesquisa de Solos. Sistema brasileiro de classificação de solos. Brasília, DF: Embrapa Produção de Informação; Rio de Janeiro: Embrapa Solos, 1999.412 p.

EMBRAPA. Empresa Brasileira de Pesquisa Agropecuária. (Embrapa Sorgo e Milho. Sistema de Produção) Disponível em 20/abr/2007: <http://sistemasdeprodução.cnptia. embrapa.br>. Acesso em: 15/jun/2007.

GASSEN, D.N. O risco da mistura de herbicidas com inseticidas em milho. In: Gassen, D.N. (Ed.) Informativos técnicos Cooplantio. Passo Fundo: Aldeia Norte Editora, p.125$128,2002$.

KARAM, D.; MELHORANÇA, A.L. Plantas Daninhas. In: CRUZ, J.C.; VERSIANI, R.P.; FERREIRA, M. T. R. Cultivo do milho. Sete Lagoas: Embrapa Milho e Sorgo, 2004. (Embrapa Milho e Sorgo. Sistema de Produção). Disponível em 20/nov/2006. <http://www.cnpms.embrapa.br/publicacoes/milho/plantasdaninhas/htm $\geq$. Acesso em: 23/jul/2007.

LÓPEZ OVEJERO, R.F.; FANCELLI, A.L.; DOURADO-NETO, D.; GARCIA Y GARCIA, A.; CHRISTOFFOLETI,P.J. Manejo de plantas daninhas na cultura do milho. In: FANCELLI, A.L.; DOURADO-NETO, D. Milho: estratégias de manejo para alta produtividade. Piracicaba: Escola Superior de Agricultura "Luiz de Queiroz", p.47-79, 2003.

OLIVEIRA JÚNIOR, R.S. SELETIVIDADE DE HERBICIDAS PARA CULTURAS E PLANTAS DANINHAS. IN. OLIVEIRA JÚNIOR, R.S.; CONSTANTIN, J. Plantas daninhas e seu manejo. Ed. Guaíba:Agropecuária, p.291-314, 2001.

RICHARDS, R.A. Selectable traits to increase crop photosynthesis and yield of grain crops. Journal of Experimental Botany, Oxford. v.51, p.447-458, 2000.

SILVA, J.B.; RODRIGUES, M.A.T.; BEGLIOMINI, E. Determinação do período de interferência de plantas daninhas em milho fundamentado nos estádios fenológicos da cultura. O Ruralista, v.35, n.440, 1998. 